\title{
Endothelial dysfunction or anything else?
}

\author{
Antonio Miceli, MD, PhD
}

\footnotetext{
From the Istituto Clinico Sant'Ambrogio, Gruppo Ospedaliero San Donato, Milan, Italy; and Department of Clinical Science at South Bristol, University of Bristol, Bristol Royal Infirmary, Bristol, United Kingdom. Disclosures: Author has nothing to disclose with regard to commercial support.

Received for publication Sept 30, 2016; accepted for publication Oct 3, 2016; available ahead of print Nov 17, 2016.

Address for reprints: Antonio Miceli, MD, PhD, Istituto Clinico Sant'Ambrogio, Gruppo Ospedaliero San Donato, Via Faravelli 16, Milano, Italy (E-mail: antoniomiceli79@alice.it).

J Thorac Cardiovasc Surg 2017;153:325-6

$0022-5223 / \$ 36.00$

Copyright (C) 2016 by The American Association for Thoracic Surgery

http://dx.doi.org/10.1016/j.jtcvs.2016.10.023
}

Chronic kidney disease (CKD) is commonly defined as an estimated glomerular filtration rate (eGFR) less than $60 \mathrm{~mL} / \mathrm{min} / 1.73 \mathrm{~m}^{2}$ for at least 3 months, with or without kidney damage. ${ }^{1}$ According to this definition, the prevalence of CKD is 63 million people in the United States, and it is associated with increased risk of cardiovascular events related to an accelerated atherogenesis in medium and small arteries. ${ }^{1,2}$ In addition to traditional risk factors (hypertension, diabetes mellitus, and dyslipidemia), several uremia-specific risk factors, such as oxidative stress, homocysteinemia, endothelial dysfunction, platelet aggregation, decreased concentration of transforming growth factor $\beta 1$, chronic inflammation and vascular calcification, may have an important role in the rapid progression of atherosclerosis inducing coronary artery disease and graft failure. 3,4

Intimal hyperplasia, hyalinosis, and smooth muscle cell hypertrophy represent the main pathologic expression of the nephroangiosclerosis. ${ }^{5}$ An increased risk of postoperative mortality and morbidity with decreased eGFR has been previously described among patients undergoing coronary artery bypass grafting. ${ }^{6-9}$ Cooper and associates ${ }^{8}$ reported that operative mortality rose from $1.8 \%$ in patients with mild renal dysfunction (eGFR of $89-60 \mathrm{~mL} / \mathrm{min} /$ $1.73 \mathrm{~m}^{2}$ ) to $4.3 \%$ in patients with moderate renal dysfunction (eGFR of $59-30 \mathrm{~mL} / \mathrm{min} / 1.73 \mathrm{~m}^{2}$ ) and to more than $9 \%$ in those with severe dysfunction. Interestingly, in patients with an eGFR less than $30 \mathrm{~mL} / \mathrm{min} /$ $1.73 \mathrm{~m}^{2}$, the use of internal thoracic artery (ITA) grafts in patients with CKD not dependent on hemodialysis was seen to be protective against operative death when compared with the use of venous grafts. ${ }^{8}$

ITA is the most important conduit used in coronary artery bypass grafting and is associated with excellent outcomes and long-term patency relative to the saphenous vein graft. The lower tendencies of ITA toward spasm and development of atherosclerosis are explained by the absence of a significant muscular component and the increased production of nitric oxide in basal and stimulated states. ${ }^{10}$ Consequently, ITA should be the first patients with CKD. function.

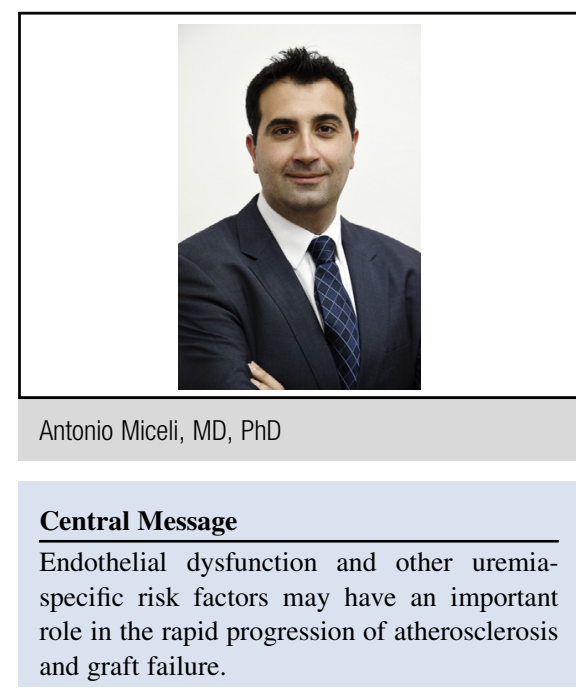

See Article page 317.

revascularization option for patients with CKD. ${ }^{11}$ Little is known, however, about the patency of arterial grafts in

In their article in this issue of the Journal, Kinoshita and colleagues $^{12}$ add evidence that endothelial dysfunction may play a significant role in the progression of arterial graft failure. Specifically, under inhibition of cyclooxygenase with indomethacin, Kinoshita and colleagues ${ }^{12}$ found that acetylcholine produced a concentration-dependent relaxation in patients with an eGFR greater than $60 \mathrm{~mL} / \mathrm{min} / 1.73 \mathrm{~m}^{2}$. This relaxation was less evident in patients with an eGFR between 30 and $60 \mathrm{~mL} / \mathrm{min} / 1.73 \mathrm{~m}^{2}$, whereas a mild contraction was observed in patients with severe CKD $\left(e G F R<30 \mathrm{~mL} / \mathrm{min} / 1.73 \mathrm{~m}^{2}\right)$, suggesting that nitric oxide was not produced by the endothelium. The relaxation was abolished in the presence of nitric oxide synthase inhibitors or endothelium removal, highlighting the importance of the endothelial function in the ITA. Interestingly, the vasodilator response to the sodium nitroprusside was comparable among the 3 levels of renal

The report of Kinoshita and colleagues ${ }^{12}$ gives us 2 important messages. First, the endothelial function of ITA grafts is always impaired at the time of coronary artery bypass grafting. As consequence, patients with CKD are at higher risk for graft failure than are those with normal renal function. Nevertheless, subanalysis of Project of Exvivo Vein Graft Engineering via Transfection (PREVENT IV) study revealed no differences in the rates of saphenous 
vein or ITA graft failure and repeat revascularization at 1 year in patients with and without CKD, suggesting that preoperative renal dysfunction has less influence on graft outcomes. ${ }^{13}$ This conclusion raises the question of whether CKD is a risk factor for worse outcomes or just the expression of several comorbidities.

Second, the use of vasodilators such as dihydropyridine calcium channel blockers might balance the mild contraction induced by the lack of endothelial function. In this setting, Fan and colleagues ${ }^{14}$ have shown that cilnidipine (a dihydropyridine fourth-generation calcium channel blocker) relaxes ITAs through the increase production of nitric oxide by enhancement of endothelial nitric oxide synthase. A dihydropyridine calcium channel blocker therefore might become the standard treatment of patients with CKD undergoing coronary artery bypass grafting surgery.

Despite these considerations, the article of Kinoshita and colleagues $^{12}$ presents several biases that might have an impact on the ratio of contraction to relaxation. Specifically, no information is reported regarding the usage of $\beta$-blockers as well as calcium channel blockers. Furthermore, the ITA was always harvested in a skeletonized manner, and trauma would potentially be present.

In conclusion, Kinoshita and colleagues ${ }^{12}$ have demonstrated that endothelial function of ITA is modified in presence of any stage of CKD. Other uremia-specific risk factors should also be considered, however, as they certainly have an important role in the rapid progression of atherosclerosis and graft failure. In the light of these results, I encourage Kinoshita and colleagues ${ }^{12}$ to perform a well-designed study looking at the long term ITA patency, taking into consideration all potential risk factors and biases for adverse outcome.

\section{References}

1. National Kidney Foundation. K/DOQI clinical practice guidelines for chronic kidney disease: evaluation, classification, and stratification. Am J Kidney Dis. 2002;39(2 Suppl):S1-266.

2. Sarnak MJ, Levey AS, Schoolwerth AC, Coresh J, Culleton B, Hamm LL, et al. Kidney disease as a risk factor for development of cardiovascular disease: a statement from the American Heart Association Councils on Kidney in Cardiovascular Disease, High Blood Pressure Research, Clinical Cardiology, and Epidemiology and Prevention. Circulation. 2003;108:2154-69.

3. Yerkey MW, Kernis SJ, Franklin BA, Sandberg KR, McCullogh PA. Renal dysfunction and acceleration of coronary disease. Heart. 2004;90:961-6.

4. Zoccali C. Endothelial dysfunction in CKD: a new player in town? Nephrol Dial Transplant. 2008;23:783-5.

5. Zoccali C. Endothelial dysfunction and the kidney: emerging risk factors for renal insufficiency and cardiovascular outcomes in essential hypertension. $J$ Am Soc Nephrol. 2006;17(4 Suppl 2):S61-3.

6. Holzmann MJ, Ahnve S, Hammar N, Jörgensen L, Klerdal K, Pehrsson K, et al. Creatinine clearance and risk of early mortality in patients undergoing coronary artery bypass grafting. J Thor Cardiovasc Surg. 2005;130:746-52.

7. Wijeysundera DN, Karkouti K, Beattie WS, Rao V, Ivanov J. Improving the identification of patients at risk of postoperative renal failure after cardiac surgery. Anesthesiology. 2006;104:65-72.

8. Cooper WA, O'Brien SM, Thourani VH, Guyton RA, Bridges CR, Szczech LA, et al. Impact of renal dysfunction on outcomes of coronary artery bypass surgery: results from the Society of Thoracic Surgeons National Adult Database. Circulation. 2006;113:1063-70.

9. Miceli A, Bruno VD, Capoun R, Romeo F, Angelini GD, Caputo M. Occult renal dysfunction: a mortality and morbidity risk factor in coronary artery bypass grafting. J Thorac Cardiovasc Surg. 2011;141:771-6.

10. Taggart DP. Current status of arterial grafts for coronary artery bypass grafting Ann Cardiothorac Surg. 2013:2:427-30.

11. Ashrith G, Elayda MA, Wilson JM. Revascularization options in patients with chronic kidney disease. Tex Heart Inst J. 2010;37:9-18.

12. Kinoshita T, Masashi T, Suzuki T, Aimi Y, Asai T, Okamura T. Endothelial dysfunction of internal thoracic artery graft in patients with chronic kidney disease. J Thorac Cardiovasc Surg. 2017;153: 325-6.

13. Mehta RH, Hafley GE, Gibson M, Harrington RA, Peterson ED, Mack MJ, et al. Influence of preoperative renal dysfunction on one-year bypass graft patency and two-year outcomes in patients undergoing coronary artery bypass surgery. $J$ Thorac Cardiovasc Surg. 2008; 136:1149-55.

14. Fan L, Yang Q, Xiao XQ, Grove KL, Huang Y, Chen ZW, et al. Dual actions of cilnidipine in human internal thoracic artery: inhibition of calcium channel and enhancement of endothelial nitric oxide synthase. J Thorac Cardiovasc Surg. 2011;141:1063-9. 